Elsevier required licence: $(c)<2018>$. This manuscript version is made available under the CC-BY-NC-ND 4.0 license http://creativecommons.org/licenses/by-nc-nd/4.0/ 


\title{
How common knowledge is constructed and why it matters in collaboration between professionals and clients
}

\begin{abstract}
Professionals are increasingly called upon to work with clients. We employ cultural-historical concepts to reveal how professionals and clients accomplish joint work on problems in services for families with young children. Professional-client interactions in day stay and home visiting services are considered, first focusing on how matters of concern are worked into departures of significance (employing 'D-analysis'), then conceptualising joint professional-parent work in terms of common knowledge and the object of activity. The importance of motives and their alignment is revealed. We show the value of $\mathrm{D}$-analysis in elucidating how common knowledge can be constructed and why this process may be problematic. Finally, we reflect on the fluid and situated nature of this kind of collaborative work.
\end{abstract}

\section{Keywords}

Cultural-historical theory; partnership; co-production; parenting; parent education

\section{Introduction}

Professionals in a range of fields are increasingly called upon to work on problems with clients, where each party recognises and responds to what is important for the other. This shift in the relational basis of practice requires professionals to exercise distinctive forms of relational expertise (Edwards, 2010). We employ cultural-historical concepts to reveal the detail of the negotiations in which professionals and clients accomplish joint work on problems in services for families with young children. The idea of co-producing, co-creating or co-constructing services - implying some kind of active involvement of end-users - is well established (Ostrom \& Ostrom, 1977; Voorberg, Bekkers, \& Tummers, 2014). This paper addresses a less well-understood aspect: co-producing a way forward for specific clients experiencing complex problems. This perspective frames the analysis in terms of communicative work and reciprocal learning, rather than in terms of client involvement in design, initiation or implementation of the service itself. The focus is on questions of motive as they come to matter in the detailed, negotiated work between professionals and particular clients. Recent research has mapped general conditions and contextual factors (such as 
level of education, trust in government) that favour active participation and outcomes of coproduction (see Parrado, Van Ryzin, Bovaird, \& Löffler, 2013; Bovaird, Van Ryzin, Loeffler, \& Parrado, 2015). While it has been suggested that there is scope at policy level to foster collective co-production for service innovation (Bovaird, Stoker, Jones, Loeffler, \& Pinilla Roncancio, 2016), the way professionals and individual clients work together and 'negotiate the interaction' (Ryan, 2012, p. 314) to co-produce ways forward for the client remains of crucial importance.

Co-production has many diverse forms, including end-users choosing service providers, contributing to prospective or retrospective consultation about service quality and design, individual actions (sorting waste for recycling), volunteering and informal contributions (such as providing infamily care), enduring relationships between institutions and organised groups of citizens, as well as ways individuals work with service providers in matters relating to their personal concern (Parrado et al., 2013). Our analysis addresses the latter, in a transformative partnership guise in which both parties' understandings of themselves, the other, and their role in the process may be reworked (Bradwell \& Marr, 2008; Ewert \& Evers, 2012). This specific notion of co-production implies citizens in collaborative relationships or partnerships with professionals, who in turn accept user expertise and work to empower clients rather than wield power over them (Ganon \& Lawson, 2008; Needham \& Carr, 2009). Our framing therefore opens up scope for conceptualizing client involvement beyond typologies of client as co-implementer, co-designer or initiator (Voorberg et al., 2014.).

The focus is on two state-funded parent education services in New South Wales (NSW), Australia. We reveal how understanding of each other's motives (common knowledge) can emerge as a critical resource in collaborative work that leads towards developments that benefit the family and mitigate risks to the child. Edwards' (2010) prior work on relational expertise is extended, making new connections between common knowledge and professional-client partnerships in relation to an undertheorised service domain (Elkan, Blair, \& Robinson, 2000).

The paper builds on and contributes to an ongoing discussion around relational work, including key arguments made previously in this journal that have subsequently been taken up more widely. Attending to new (relational) forms of practice requires a shift in analytic focus from individual action to action with others (Edwards, 2005). This early paper outlined connections between Vygotskian concepts of mediation and a concept of relational agency - a capacity to work with others to expand the object being worked on. This "recognises the importance of pre-existing 
personal understandings gained in other situations in mediating interpretations of new situations, and argues for attention to the negotiations that individuals made as they work in and with the social" (p. 172). In a subsequent paper Edwards (2011) extended this cultural-historical framework for understanding relational work, arguing that relational agency is mediated by common knowledge built at the boundaries where professional practices intersect and a feature of relational expertise required in collaborative work on complex tasks. Common knowledge is the central concept in the present paper, which adds to Edwards' (2011) paper in two key ways. First, it explores common knowledge in work between professionals and clients. The development and application of this concept have focused more on work between professionals or integrated care (see Nuttall, 2013; Stuart, 2014) - even when patient engagement is at issue (Casimiro, Hall, Kuziemsky, O'Connor, \& Varpio, 2015). Second, it links this concept with aspects of Middleton's (2010) 'D-analysis' - an approach that attunes analytically to participants' concerns.

\section{Risk, prevention and partnership}

The 'risk and protection-focused prevention' paradigm (France \& Utting, 2005) shifts from viewing problems in terms of disadvantage to considering risk and what might prevent the negative effects of risk from being actualised (Edwards, 2007, 2009). NSW policy foregrounds the need to identify risk factors and vulnerability, aiming to assist families in the transition to parenthood, build on strengths, and enhance parents' resilience (NSW Health, 2010a, 2010b, 2011). Targeted programs and services support families with young children at risk, with home visiting an internationally common example (Baggens, 2004; Hall, Slembrouck, Haigh, \& Lee, 2010; Heritage \& Sefi, 1992). In NSW, day stay services are also accessed by families where risks have been identified.

The shift in the relational basis of professional work is also relevant. Rather than services provided by professionals for clients, it is increasingly common to view practices as unfolding with clients. Taking up the notion of co-production focusing on interactions between professionals and clients as they work together on specific problems (see above), we explore these issues specifically in relation to risk and prevention services around families with young children (Fowler, Lee, Dunston, Chiarella, \& Rossiter, 2012). From a cultural-historical stance, Edwards (2010) refers to a 'relational turn' in expertise, highlighting implications for how we understand professional practice and the negotiations that occur between professionals and clients. ${ }^{1}$ 
The partnership approach to working with clients is one manifestation of co-production, and it has emerged alongside the risk and protection paradigm. Within prevention services, partnership has varied specifications and models. However, common features include a relational focus, power sharing, joint decision making, and client autonomy (Hook, 2006). Partnership counters 'expert-led' approaches known to be associated with client frustration and avoidance, and the risk of parents feeling judged and excluded from decision making (Edwards, 2007; Hopwood, 2016a, 2016b; Davis \& Fallowfield, 1991). Focusing on universal home visiting with new mothers in Sweden, Baggens (2004) found that the dominance of nurses and a task focus can "make it difficult for parents to bring their own questions and concerns into the discussion” (p. 26). Alternatively, reframing professional-client work in more relational and responsive (though not symmetrical) terms is manifest in Family Systems Nursing (Wright \& Leahey, 2009), the McGill Model of Nursing (Feeley \& Gottlieb, 2000) and the Family Partnership Model (FPM) (Day, Ellis, \& Harris, 2015). In the services studied, FPM has been implemented as part of a wider adoption across Australia.

The FPM is a model of partnership for family services and a delivery mechanism for professional education that enhances communication and collaborative skills. It promotes a strengths-based, approach in which professionals develop parents' confidence and capacity, working together towards their stated goals (Day et al., 2015). Intervention studies associate FPM with enhanced outcomes measured in terms of parent-child interaction and psychological functioning of family members (Davis \& Meltzer, 2007; Day \& Harris, 2013). However, working in partnership places specific demands on professionals, who may be uncertain about drawing on and using their specialist expertise without compromising the idea of partnership (Hopwood, Fowler, Lee, et al., 2013; Day \& Harris, 2013; Harris, Wood, \& Day, 2014; Fowler, Rossiter, Bigsby, et al., 2012). An analysis of handovers between professionals suggested cultural-historical concepts of common knowledge, relational expertise and relational agency can provide insights that address this problem (Hopwood, Day, \& Edwards, 2016).

We therefore depart conceptually from notions of advice-giving (Heritage \& Sefi, 1992) or knowledge transfer (see Fowler \& Lee, 2007). Instead we extend a body of research that demonstrates the role of reciprocal learning between professionals and parents (Hopwood, 2014, 2016a, 2016b; Fowler, Dunston, Lee, et al., 2012). Although a preliminary link between partnership and cultural-historical concepts of the zone of proximal development and mediation has been established (Hopwood, 2015), questions of motive, central to a cultural-historical approach, have 
not been fully explored in empirical analyses of professional-client negotiations. By focusing on Edwards's concept of common knowledge, and by connecting this with concepts that attune to professional-client interactions, this paper expands understanding of partnership between professionals and clients.

\section{Conceptual framework}

Common knowledge (Edwards, 2010, 2011, 2012, 2015, 2016) consists of the motives that each participant brings to working on a problem. While often considered in relation to professionals from different practices working with each other, it has also been used to explain how, for example, teachers can work productively with parents (Rai, 2014, 2016). Furthermore, Edwards (2010) has observed there is considerable scope for examining the potential of the concept in understanding professional-client relationships.

What imbues the concept with particular value and distinguishes it from everyday notions of 'knowing where someone else is coming from' is its embedding in a theoretical tradition rooted in the work of Vygostky (1960/1997) and Leont'ev (1978). Common knowledge, as knowledge of the motives that arise in different practices, can become a resource that mediates how people respond and work together on complex problems (Edwards, 2016). In this sense common knowledge can be seen as what Vygotskian theory labels a second stimulus (Vygotsky, 1960/1997). The first stimulus is the problem being worked on and the second stimulus consists of the cultural resources or tools used to work on the problem. We suggest that common knowledge is a crucial second stimulus, enabling professionals and clients to work together on, for example, a child's developmental trajectory.

Edwards (2016) writes of motive in terms of what matters to people in the practices they inhabit. Knowledge of what matters to those one is working with can help understand their reasons for acting, valuing, and responding in particular ways (Derry, 2008). Common knowledge therefore does not imply that these 'what matters' must be(come) the same. Indeed, the different insights associated with different motives are seen as strengths in partnership approaches. Edwards (2012) notes resonance between her conceptualisation and that of Carlile (2004), who studied knowledge mobilisation in the semi-conductor industry. He refers to the "capacity of common knowledge to represent differences and dependences now of consequence" (p. 557). Efforts need to be made to align motives to avoid conflict and confusion. This alignment is accomplished through listening to, 
recognising, revealing, and engaging with others' motives. Understanding how motives differ does not imply working to eradicate such difference, but rather working with it and exploring what it means for unfolding collaborative work.

The concept of motive employed here is rooted in Leont'ev's (1978) work on object of activity and object motive. The object is what is being worked on, for example, a child's trajectory. However, the object motive when working on the trajectory is likely to differ between professional and parent. Personal object motives arise through one's actions in activities in practices, hence people bring a sense of what matters for them to the interpretation of the problem. For the professional the concern may be how the child acts in developmentally appropriate ways; while for the parent the concern may be about creating some order to the day. Thus the same problem may call forth different motivations and different approaches. We therefore distinguish between object, what is being worked on, and goal, what one hopes to accomplish (an important distinction given the goaloriented nature of FPM and other partnership models ${ }^{2}$ ). We suggest that the differences in partners' motives and interpretations alert us to the need to reveal objects of activity and the motives they call forth when undertaking partnership work. Eliciting object motives and being explicit about one's own motives as a professional are crucial elements in building common knowledge as a resource.

Studies of home visiting and similar services highlight the significance of communicative features in creating asymmetries that may prevent attention being paid to parents' concerns (Baggens, 2004), and in accomplishing boundary work between professionals and clients (Hall et al., 2010). Hence an analytical approach focused on communication holds promise in revealing whether and how common knowledge is communicatively constructed. For this, we turn to Middleton's (2010) approach to the analyses of discourse, which was first used to examine how professionals from different practices learnt and accomplished collaboration. Known as the D-analysis, it offers a way of examining communicative action in the process of building the potential for collaboration. The focus D-analysis places on communicative sequence and consequence, together with its attention to participants' concerns, allows us to trace the construction of common knowledge.

D-analysis is based around a series of five concepts that describe how relevant distinctions (matters of concern) relating to details of practice are established, made to stick, and worked up to make a difference (Middleton, 2010). The first concept is deixis, which has to do with how participants in an interaction nominate, draw attention to or point to a distinction. This may (or may not) be worked up to change subsequent talk turns. Next comes definition and delineation - how an issue is 
taken up by others, including through qualifications, ordering and expansive elaborations.

Deliberation refers to the emergence of a working consensus evoking both general and particular features. The remaining two concepts address the 'contingent consequences' of such work around distinctions. Departure involves qualitative shifts towards different positions in practices, marked by formulating new distinctions. Development refers to participants specifying new ways of working (together) that become the basis of reformulated practices and the warrant for regarding such changes as significant. Table 1 shows how we framed these concepts specifically in relation to professional-client work: looking for distinctions (matters of concern) and how they become resources that engage participants in further exploring their joint work.

Table $1 \quad$ D-analysis concepts in use

\begin{tabular}{|l|l|}
\hline $\begin{array}{l}\text { D-analysis } \\
\text { concept }\end{array}$ & Application in the present study \\
\hline Deixis & $\begin{array}{l}\text { What matters, what is at issue, nomination of topics for discussion, what is } \\
\text { taken up (or not) in the interaction }\end{array}$ \\
\hline $\begin{array}{l}\text { Definition/ } \\
\text { delineation }\end{array}$ & $\begin{array}{l}\text { Asking for/provision of examples, further details, contextual parameters, } \\
\text { explanations of significance to parent, acknowledgement of importance by } \\
\text { professional }\end{array}$ \\
\hline Deliberation & $\begin{array}{l}\text { Negotiation around what applies to this family; challenge of unhelpful } \\
\text { constructs, (dis)agreement in (re)interpreting problem }\end{array}$ \\
\hline Departure & $\begin{array}{l}\text { Changing position of professional and parent in relation to each other; } \\
\text { changing concept of parent role in specific parenting practices (expanded } \\
\text { object) }\end{array}$ \\
\hline Development & $\begin{array}{l}\text { Functional partnership as basis for joint work. } \\
\text { Reformulation of parent practices in relation to child now enacted (or } \\
\text { commitment to act), based on new joint responses to problem, evaluative } \\
\text { criteria and tools }\end{array}$ \\
\hline
\end{tabular}

(drawing on Middleton, 2010)

Unlike the study in which Middleton developed the D-analysis, our focus is not on professional learning in interagency work, but on interactions between professionals and parent clients. We have not worked with transcripts of video- or audio-recordings (as Middleton did) because ethnographic methods meant data were in the form of hand-written notes of interactions. The categories shown in Table 1 were used to reveal how concerns, what matters, and motives were made visible and worked with in interactions between professionals and clients.

\section{$4 \quad$ Empirical details}

Data collection involved observation of interactions between professionals and clients in home visiting (also called outreach) and day stay services provided by organisations in three of eight 
Local Health Districts (LHDs) around Sydney, NSW. In total 22 day stay and 30 outreach interactions were observed, involving 15 professionals and 43 families. The selected LHDs spanned urban, suburban and outer areas of Sydney metropolitan area. Specific services within these were sampled based on opt-in at the service level by relevant managers, whose staff then elected to participate individually. Over a four-month period, these professionals nominated families they were working with, who were contacted by an administrator. Participation was subject to informed consent, and names of organisations, places and people are pseudonyms.

The home visiting services involve multiple visits by a nurse to a family in their home, lasting around an hour, at a frequency determined by parents' requests and the perceived level of risk. In day stay services, families attend a special centre for six or seven hours, where they mainly work with a nurse, but can also see 'allied health' practitioners, including a psychologist (see Hopwood \& Clerke (2016) for more details). Most day stay clients are discharged after two or three visits, and they may receive follow-up home visits.

Aligning with the risk and prevention paradigm, services for families with children in NSW are managed within the State's policy of care-service response, which is determined by risk factors in the context of a parent's strengths, family and local resources (NSW Health, 2010a, 2010b, 2011). Often, a particular level of risk prompts access to a service at a matched level, as outlined in Table 2.

Table 2 Service levels and risk factors in NSW child and family services

\begin{tabular}{|l|l|l|}
\hline Level & Service category & Examples of risk factors \\
\hline 1 & $\begin{array}{l}\text { Universal (e.g. midwifery, childhood } \\
\text { health clinics, parenting groups) }\end{array}$ & No specific risk factors identified \\
\hline 2 & $\begin{array}{l}\text { Early intervention and prevention (e.g. } \\
\text { day stay clinics, specialist services) }\end{array}$ & $\begin{array}{l}\text { Young mother; multiple, premature or } \\
\text { complicated birth; chronic parental disability } \\
\text { or illness; anxiety, depression, history of } \\
\text { mental health disorder; financial stress; } \\
\text { unstable housing; isolation, refugee status }\end{array}$ \\
\hline 3 & $\begin{array}{l}\text { Complex parenting needs where co- } \\
\text { ordinated team management approach is } \\
\text { required (e.g. drug/alcohol services, } \\
\text { domestic violence services, needs- } \\
\text { specific Level 2 services) }\end{array}$ & $\begin{array}{l}\text { Problematic substance use; diagnosed mental } \\
\text { illness (e.g. bipolar disorder); current or } \\
\text { history of domestic violence; current or } \\
\text { history of child protection issues }\end{array}$ \\
\hline
\end{tabular}

(based on NSW Health, 2010b)

Our analysis focuses on two cases. These do not represent broader quantifiable patterns across the wider dataset, but are illustrative of conceptual findings that arose repeatedly in data from both services. This paper develops a conceptual argument relating to nuances of professional-client 
interactions. A detailed consideration of two contrasting cases provides an appropriate means to both demonstrate the empirical basis of the overall argument, and to illustrate how theoretical ideas are manifest in practice. For this reason, we do not refer further to the larger dataset.

The two cases discussed in detail below were selected on the basis of contrasts noticed in prior analyses (Hopwood \& Clerke, 2016) that indicated they would be particularly relevant given the purpose stated above. Both were described by the professionals as challenging, suggesting they could help elucidate the demands of partnership work. The case of nurse Sarah and the Kelly family in day stay stood out because the work on feeding and sleeping unfolded in very different ways. The case of Sophie, a nurse visiting the Cooper family, was notable because of the mother's acute anxiety, concerns about her self-harm, and the way in which Sophie engaged with her. The issues worked on in these cases (sleep, settling, parent mental health, feeding, etc.) are typical of those that arise regularly in home visiting and day stay work.

We used categories offered by the D-analysis to track sequence and consequence in interactions, at a turn-by-turn level. Deixis, delineation, deliberation, and departure were identified in the written notes for each case. As development refers to changing relations between parents and elements of parenting practices, we note pointers to development, rather than claiming evidence of developments within each interaction. Edwards' (2016) concept of common knowledge was then used to conceptualise differences between and within the two cases at the analytical level of the activity setting.

\section{D-analysis of professional-client interactions}

\section{Sarah and the Kelly family}

Bik and Lee Kelly attended a day stay service with their nine-month-old daughter Rachel. Bik was referred by her GP as a Level 2 client. Pertinent risks were Bik's history of depression and ongoing difficulties adjusting to parenting, and concerns about Rachel's nutrition because her weight had dropped several percentile points. This six-hour interaction followed a linear structure, with two breaks while Sarah attended to a different family. Important distinctions can be drawn between the work that focused on sleep and the work that focused on feeding. Right at the beginning, Bik nominates a theme (deixis) that recurs through the interaction:

Bik: She'll tell you what she wants. And what she doesn't want. 
Sarah: $\quad$ How do you respond?

Lee: $\quad$ We are suckers! We concede too much.

Sarah's question offers the opportunity for the parents to delineate by linking the description of the child to the parents' actions. Lee's response suggesting over compliance points to a key issue of negotiation between Sarah and the parents that is never fully resolved. Sarah then asks what has been happening, and Bik describes her daughter's frequent night waking, and how she's not interested in food at all. Sarah then asks whether Rachel helps herself with food, and Lee responds “No, never!" Bik mentions that Rachel turns her face away when she tries to spoon food into her mouth:

Sarah: Why do you think she does that?

Bik: $\quad$ Because she doesn't want food.

Bik's response connects with the recurring idea of following Rachel's preferences, and Sarah does not (yet) confirm, acknowledge or contest this interpretation. There follows discussion of gag reflex, breastfeeding, and sleep patterns. Sarah helps Bik delineate by asking how and where Rachel falls asleep:

Bik: I try in the cot once a month. She's very unpredictable. So we respond. She tells us what she wants and doesn't want.

Sarah: It sounds like you are very accommodating of her.

Lee: $\quad$ Yes.

Sarah: What do you want to achieve?

Bik: $\quad$ Everyone is concerned she's small. If there is a way to help her eat better, and sleep better, we want to know.

Lee: $\quad$ And to reduce the night waking. The doctor said her weight was on a plateau.

At this moment Rachel grizzles and pulls her ear, which is interpreted as a tired sign. Sarah asks the parents to follow her guidance in settling practices that are new to the family. Having delineated that Rachel doesn't normally sleep in any kind of bag or wrap in the day, Sarah attempts to build consensus around a different approach:

Sarah: $\quad$ She'll need your support to feel okay in the cot today. Are you happy to try 
wrapping her with one arm left free?

Bik: $\quad$ You can try but she never liked being swaddled.

Sarah: I'm thinking some snugness will help her feel cosy, because she's not in your arms or the carrier. We will listen to her and bit by bit help her to feel relaxed, safe and snug.

Although Bik consents, she seems sceptical of the departure. Sarah then introduces a new distinction: helping the child feel relaxed and safe. While this seems close to following what Rachel wants, it transpires this actually constitutes a difficult departure for the parents. Bik follows Sarah's suggestion to give Rachel a cuddle, place her in the cot, and move away while she is calm. Following this, Sarah moves between offering opportunities for delineating and deliberating. She asks questions about what happens during settling at home, and how they interpret what is happening now (“Would you say she’s OK?”). She explains: "We want to challenge [the child] without them getting to that stressful state." This idea of challenging the child is a major departure that has not yet been clearly recognised or expressed as such. Bik follows Sarah's suggestions, and a few cycles ensue of Rachel calming with her parents' help, then escalating when left alone. Rachel begins to cry more strongly:

Bik: $\quad$ She's starting to get upset.

Sarah: $\quad$ She's saying “I don't know what to do. I need your help.” Keep body rocking, she's got lovely support. Persist a bit before she escalates to the next stage.

Bik deliberates, and Sarah responds by offering an alternative interpretation of Rachel's cries, attempting to build the parents' agency in relation to the child (by offering challenge with support), rather than being totally led by her. Several times, when Sarah checks with the parents, they pull the interaction back to deliberation:

Sarah: $\quad$ We've helped her to relax. How do you feel?

Bik: $\quad$ She's upset. I want her to sleep.

Sarah: $\quad$ Sometimes she needs to vocalise to get there.

Bik: $\quad$ She does but she gets upset ... she doesn't normally cry this much.

A similar exchange of differing interpretations continues: "She's upset" versus "she's complaining," and "she's so worked up she won't settle" versus "” have faith you can calm her down." Bik 
maintains her view, saying they are "trying to make her do something she doesn't want to do," and "I'm frustrated. I came because of the eating, and part of that is rest. I feel we're robbing her of rest." Sarah suggests that Lee take Rachel in his arms and settle her to sleep. The discussion between Sarah and Bik continues, prompted by Bik saying she knows she is "wussy" and that Rachel will fall asleep in her own way if she wants to.

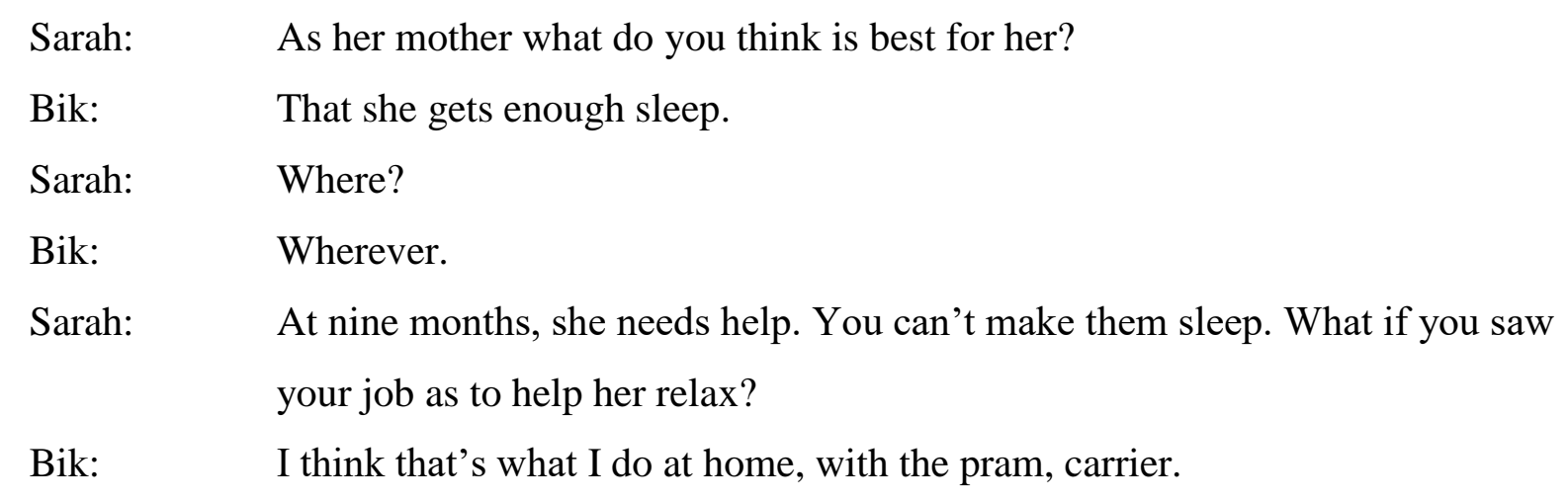

Here a divergence surfaces between Sarah's concern and Bik's indifference to where Rachel sleeps. While Bik accepts the idea of helping Rachel relax, she doesn't see that this involves any departure from her home practices. Sarah dwells in this deliberative mode:

Sarah: $\quad$ You said you were thinking you're trying to make her do something she
doesn't want. Bik: Yes.

Sarah: $\quad$ Could it be that you're helping her do something that is hard?

Bik: I suppose.

Sarah: $\quad$ That takes time. At nine months that is a different person from at four months.

Bik: $\quad$ But she was saying "I'm not going to sleep this way" and now she's over tired. I'm trying to make it easier for me and her.

Sarah soon leaves to attend to a second family. Their next interaction focuses on Rachel's feeding, and unfolds in significantly different ways. Sarah starts by asking Bik and Lee to put some chunky bits of food in front of Rachel and "see what she does". She encourages the parents to eat with her, and suggests they try bigger chunks when she notices Rachel struggling to grip the smaller pieces. The overriding characteristic here is one of departure, with Sarah highlighting new distinctions that shift the relationship between the parents and child in a feeding activity. 
Sarah: $\quad$ Focus on each other and enjoy your food. She might be feeling pressure if you're looking at her all the time ... see, she's exploring putting the cracker in her mouth. She's quiet, she's having a nice time so far, just part of the group. For meal time to go well and for her to enjoy and expand her taste, it needs to be relaxed, no pressure, just the opportunity to explore.

Bik (to Lee): See, that's what I say!

Lee: $\quad$ She keeps pushing it in [a large piece of cracker].

Bik: $\quad$ She'll work it out.

Sarah: $\quad$ Exactly! To work it out she needs practice. That gag reflex is a safety mechanism.

Bik: It's probably better for her to hold when it's bigger.

Sarah: $\quad$ Exactly. Around nine months that pincer grip will come into play. It's all about fun time, exploring food. You can't make them eat. If she has a good time, she will come back for more.

Bik: $\quad$ Yes, she's relaxed now, [to Lee] because you're not shoving food in her mouth.

Later, Sarah comments that Rachel is "showing us she likes to feed herself" and Bik replies, "I think she prefers it herself." These ideas share a connection to Rachel's wishes, but Bik's interpretation has changed from her previously stated idea that Rachel doesn't want food; she follows Sarah from this point of departure. Sarah leaves to attend to the other family before a second attempt at settling Rachel. It suffices to illustrate how the interaction switched back to the more contested form. Sarah's attempts at departure were repeatedly pulled back into deliberation by Bik. Before the excerpt below, Sarah prompts Bik to come out of the nursery having helped Rachel calm down in the cot, saying "You brought her level down, it's a lovely learning curve for her," to which Bik replies:

Bik: $\quad$ I don't see why this is necessary. We can get her nicely to sleep on her own terms. Why do we need to do this?

Sarah comes back to this later, when Rachel is asleep:

Sarah: $\quad$ You're asking why we need this? As she's growing older now, she'll need you to help her self-regulate, to control her emotions. And self-settling is an 
important part of that bigger learning process. She learns that when her level of stress goes up, you come in and bring it down.

Bik: $\quad$ I felt the opposite, that I was escalating her.

And shortly after:

Bik: She's good at learning stuff. I rely on her working it [self settling] out herself.

Sarah: $\quad$ She'll work lots of things out herself. But this is something you can help her with.

This dialogue continues, and Bik maintains her position: "I didn't feel like she was learning to selfsettle." Sarah's departures are met with a pull back to deliberation by the parents. After some further discussion, the parents wait for Rachel to wake and then they go home.

\section{Sophie and the Cooper family}

Masha Cooper was visited in her home by Sophie many times over several months. Her son Morgan was two-and-half months old at the time of research. As a Level 2 risk client, Masha was referred first to a day stay service because of her history of depression, then to the sustained home visiting service. Two visits were observed, three weeks apart. Prior to these, Sophie worked with Masha to overcome difficulties she had leaving her home with Morgan, due to acute anxiety about threats to his health. She had not been able to take him out in the pram for fear he would be hit by a car.

In terms of structure and sequence, these interactions are more chaotic than in the Kelly family case. Masha nominates many issues, and both she and Sophie loop back to former points of deixis: Morgan's bowel movements, a pimple, playfulness, settling, bronchiolitis and a visit to the hospital, meeting a friend, a blood test, Masha's weight and body image, cutting and washing Morgan's hair, mittens, unsettled behaviour, post-natal depression, conflict between the parents and with Masha's mother-in-law, contemplation of suicide or self-harm, going to a shopping centre, cradle cap, and Masha's self-care. The excerpts below are indicative of the interaction across all the topics just listed, including recurrence of Masha's anxiety that Morgan might be, or become, unwell. The first point of deixis relates to Morgan's bowel movements:

Masha: $\quad$ The last two days, he didn't do a poo. Is that normal?

Sophie: Has he done that before? 
Masha: $\quad$ No. I'm worried something is wrong again.

Sophie: $\quad$ Well that can be perfectly normal, especially with breastfed babies.

Masha: $\quad$ Oh. It looked like diarrhoea, but it wasn't.

Sophie: How did you know it wasn't diarrhoea?

Masha: $\quad$ Well because the early childhood nurse told me if it was it would be very smelly.

Sophie: $\quad$ And it wasn't smelly?

Masha: $\quad$ No.

Sophie's response delineates in relation to the child's history. As they deliberate, Sophie normalises, seeking Masha's own knowledge as a way to reach consensus based on alignment between the professional and parent. A slightly different version of this arose when Masha noticed something more positive, describing Morgan's increased playfulness and excitement:

Masha: $\quad$ Now he likes the playmat a lot, he gets very excited.

Sophie: What does he do to let you know he's excited?

Masha: $\quad$ Oh, he smiles and laughs. When I'm holding him sometimes, we just look at each other for a moment and he smiles, or giggles.

Sophie: $\quad$ Those little stops, when you gaze together and wonder, they are like food for his brain. He's got this big exciting world he's just getting to know, and you're helping him connect all the stars together.

Masha: $\quad$ Oh.

The move from deixis to delineation again involves asking for concrete detail, which then moves towards departure as Sophie re-casts what has been described. Masha's "Oh" suggests this is new to her. However, Masha then raises his playfulness as a point of concern:

Masha: $\quad$ Is that just him, or is it all babies? Is it normal?

Sophie: What do you think?

Masha: $\quad$ Maybe it's too early like this.

Sophie: Well, not all babies are able to do that yet, enjoy that play on the mat, and have those moments with you. But it's wonderful if they can. That's a wonderful gift you're giving him.

Masha: $\quad$ Dad is good at the play too. 
Masha nominates a connection between playfulness and normality, and Sophie delineates by probing Masha's own insights, before moving to deliberation and departure that challenge her concern. Masha accepts, noticing positive qualities in her husband's play. When Masha raises the prospect of taking Morgan for a blood test, her anxiety about going out on foot emerges:

Masha: $\quad$ Is that safe?

Sophie: $\quad$ Are you concerned about cars when walking?

Masha: Yes.

Sophie: What would make you feel safe, then, walking?

Masha: $\quad$ To the hospital is fine, because it is quiet and I can use the baby carrier.

Sophie: Is he getting heavier in the carrier?

Masha: Yes.

Sophie: $\quad$ So maybe the pram could be something good for you. What is it that makes that difficult for you?

Sophie offers opportunities for delineation through questioning that legitimises Masha's concern, soliciting her own reasoning of what might help, hinting at the pram, which would be a major departure for Masha. Later, Masha reveals that she wants to lose weight, doesn't like looking at herself in the mirror, and is thinking of running in a gym.

Sophie: When we breastfeed it's important we gain weight, because that's where we store the extra energy we need.

Masha: Oh, really?

This leads to departure in a plan for Masha to undertake walking to a local park or to a mothers' group as exercise, rather than in a gym. Storing energy for breastfeeding and maintaining social contact align with what matters to Masha. However, Masha associates walking outside with the prospect of having to take Morgan back to hospital because he might catch whooping cough. Sophie suggests that this anxiety is something a psychologist could help her with, and Masha accepts the offer of a referral. Thus one departure loops back into further deliberation, producing a new departure.

In the first exchanges of the second visit, Masha nominates several issues, including Morgan crying 
a lot, not sleeping, hating his pram and dummy, her belief that she has post-natal depression (PND), her losing control (screaming, "going crazy", breaking things), and high anxiety caused by conflict with her mother-in-law. Each time, Sophie takes up Masha's deixis by acknowledging or asking a question (e.g. "I agree this is a really hard time for you"), but the topics don't develop as Masha introduces new ones in quick succession. The whole visit involves rapid cycling between topics, with Sophie and Masha returning to different issues: Masha often to her mother-in-law, Sophie to Masha's self-care and Morgan's wellbeing. The question of Masha having PND develops more the third time it is mentioned:

Masha: $\quad$ For two weeks I had all the symptoms of PND.

Sophie: What are those symptoms?

Masha: $\quad$ I Googled it. My mother-in-law told my husband I have PND because I'm too emotional and irrational so I Googled it.

Sophie: Which symptoms did it say that you think you have?

Masha: $\quad$ I'm oversensitive, and getting angry and anxiety - they are all part of PND.

Sophie: $\quad$ Yes they are. What about reconnecting with the psychologist maybe?

Masha: $\quad$ I might go back to [one she had seen before].

Sophie: $\quad$ I can let her know if you like.

This sequence moves quickly from delineation towards deliberation and departure, with Sophie's responses legitimising Masha's concerns. A few moments later:

Masha: $\quad$ I did get to the point when I thought I would jump off the balcony. Just for a second. The sleepless nights, the screams, I can't even eat. He can't even sit. He just screams.

This presents several points of deixis, and Sophie delineates all of these at some point in the visit. She immediately follows up with "I wonder what he's feeling when he is screaming," which leads to deliberation ending in Masha saying she can get him to sleep if she breastfeeds him on the bed. Then Sophie returns to another point:

Sophie: Okay. I'm concerned about the balcony.

Masha: $\quad$ I wouldn't do it.

Sophie: I'll give you a number for you to use in those moments. And one for an adult 
mental health line.

Masha: $\quad$ My mother-in-law tells me just deal with it. She says I'm isolating her from Morgan because I want other friends to see him sometimes.

Sophie: What can you do?

Masha: $\quad$ I told my husband not to tell me what she says critical about me. Not to forward her emails.

Sophie: $\quad$ That sounds good. Here's that number, stick it somewhere and especially if you're home alone with Morgan and have those thoughts, put him in the cot, walk out and call this number.

The deliberation and departure are shaped by Sophie's questions and responses, accepting Masha's conflict with her mother-in-law, and drawing on and the mother's capacity to work out ways to manage the situation. Masha switches rapidly between issues, and Sophie repeatedly offers the same departure in the form of different reasons explaining Morgan's behaviour:

Masha: $\quad$ Before I could take the pram, put him in it and go for a walk, but now he's screaming.

Sophie: $\quad$ I wonder if he is really overtired and saying "Oh Mum, it's too hard"?

Eventually Morgan appears tired, and so Masha puts him in the cot. Sophie replies to Masha's question "What's wrong with him?" by again suggesting maybe he is tired, and asking:

Sophie: What do you think you can do to help him have the opportunity to learn to sleep in his bed?

Masha: $\quad$ I don't know.

Sophie: I'm hearing you've lost that pattern today. Trying lots of different things, maybe now he's older and so busy, that makes him excited, something different every time.

Masha: He hates the Banksia ways [approaches to settling Masha had learned in a tertiary service].

Sophie: Hates?

Masha: $\quad$ Cries, wants to be picked up.

Sophie: Maybe he's learning that he's different from you.

Masha: $\quad$ Yes, he knows me best of everyone. 
Sophie: $\quad$ The place he feels safest is with you.

Masha: I'd leave him until he goes mental then let him scream ten minutes then pick him up, then after two hours, breastfeed.

Sophie: $\quad$ Maybe he doesn't know the difference between tired and hungry.

Masha: $\quad$ Maybe because he sleeps so much overnight he's not tired.

Sophie: $\quad$ He does need some sleep in the day.

Masha: But that is impossible.

Sophie: $\quad$ You can give him the opportunity, without changing every time, just give him a pattern.

The deliberation between Sophie and Masha is not straightforward or without divergence. However, it leads to changed interpretations and actions: Masha agrees she will attend to him before his cries become screams, offer a sleep environment after an hour-and-a-half of up-time, and that a cuddle with her is his safe place. Sophie comes back several times with comments like "But you're stressed, which is why the psychologist is important," and "Remember these numbers, put them on the fridge on a good day so they are there for a bad day." Sophie agrees to come back a week later, then Masha raises her difficulty coping again:

Masha: $\quad$ Two days ago was really bad. It was really hard for me not to do something stupid.

Sophie: Thanks for telling me. It's good that you talk to your husband about it, and see the psychologist.

Masha: $\quad$ This is so hard.

Sophie: $\quad$ So have that plan. Put him down, then?

Masha: $\quad$ I call the line.

\section{Discussion: what matters, and common knowledge}

These two cases will now be discussed in terms of common knowledge, linking them to the Danalyses highlighted in the accounts above. The focus is therefore on what matters to the parents and professionals, and the work done bringing different motives into alignment (or not).

What matters to Bik is responding to what her daughter wants and doesn't want. The strength of her 
attachment to this idea is not immediately apparent, and Lee's initial comment appears to make this open to deliberation. Rachel's eating and sleeping are nominated, but it transpires that Bik is more concerned about feeding and sees sleep as linked to this. How and where Rachel falls asleep are not important to the parents, rather they are concerned about the amount of sleep and reducing night waking. Bik's motives in settling are for it to remain "easy for me and for her". With regard to eating, Bik is motivated by concerns about weight loss.

Sarah shares the parents' concern for Rachel's dropping weight percentile and sleep patterns as important to her development. What matters to Sarah in working on this object is strengthening the parents' agency in relation to the child: supporting Rachel to learn to self-settle in the cot, and ensuring Rachel is relaxed around food and given the chance to explore different foods safely. Figure 1 represents this situation.

Figure $1 \quad$ Dual presence and absence of common knowledge (CK)
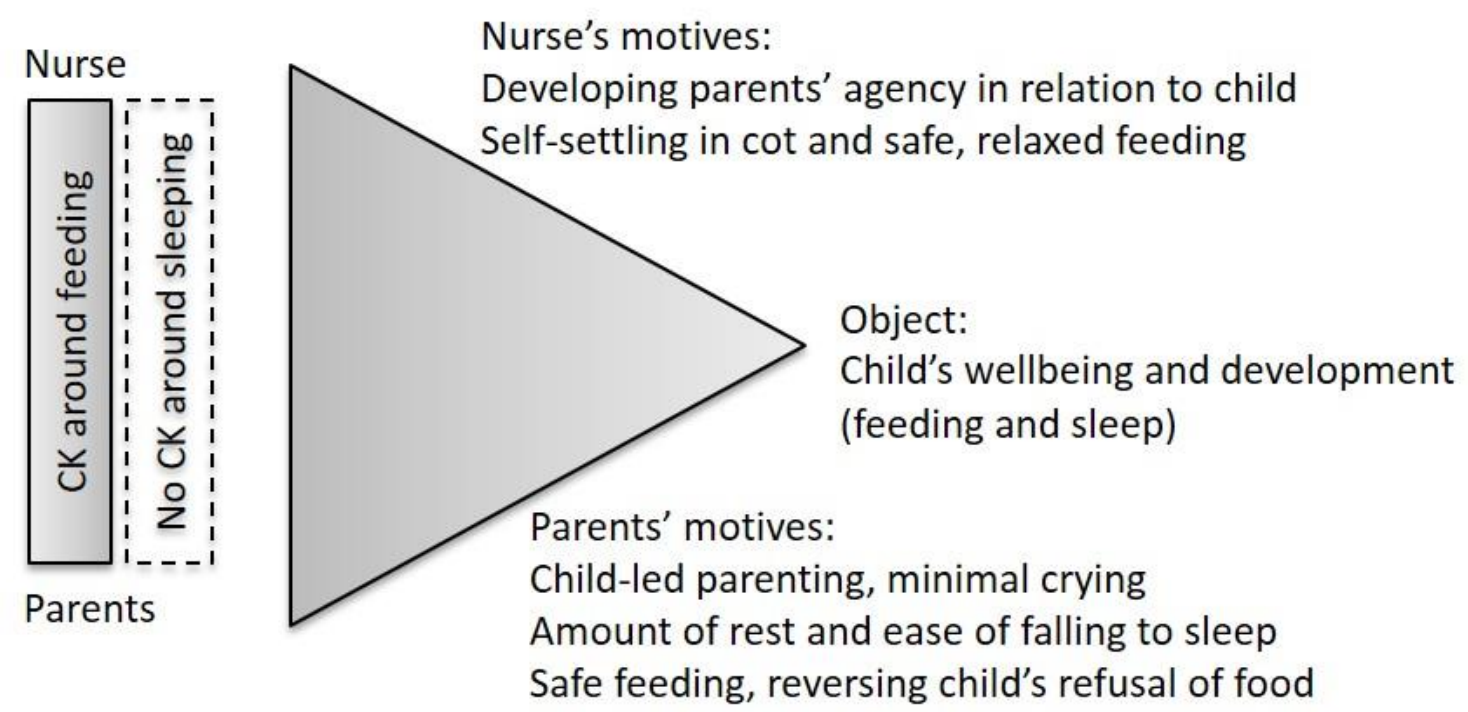

Sarah's efforts at delineation and deliberation do not bring her motives around sleeping into alignment with those of the parents, despite attempts to make her reasoning available as a persuasive device. Thus, departures based on new distinctions such as parent-led settling and challenging the child are resisted by the parents. Sarah's mention of "in the cot at first" is a departure aligned with motives of self-settling in a safe sleep space, but not with what matters to Bik, namely maximum rest obtained in the easiest, most child-compliant way. Rather than advancing from departure toward motivated commitments to new practices (development), the parents loop back to deliberating the same issues. 
By contrast, points of alignment at mealtime are repeatedly established and confirmed verbally by Sarah to the parent when she asks what they observe in Rachel. Relatively little work is needed to align motives here. Sarah's motives of being relaxed and giving Rachel more control line up with what matters to the parents - namely avoiding upset and child-led parenting. Bik sees the departures as a means to work on the object of Rachel's food intake that is consistent with what matters to her, as does Lee, whose practices are subject to more direct challenge. The departures provide a basis for reframing the relationship between the parents and elements of their parenting practices.

The distinctions involved in departures in the sleeping and feeding episodes are similar, but the parents' response to them is very different. In the latter, mutual understanding and recognition of what matters to the others becomes a tool that resources the joint work. This is not the case with sleeping, represented in the 'empty' box in Figure 1: divergence of motives becomes entrenched, hence the difficulty of arriving at distinctions and departures that the parents commit to. This can be explained in terms of the (mis)alignment of motives and the presence or absence of common knowledge as a resource that enables transformed relationships between the parents, child and professional.

Why might the interaction unfold this way? This was not typical of the parents' responses to Sarah. Rachel's first tired signs came very early in the interaction, before Sarah had the chance to thoroughly explore what matters to the parents and their settling practices. Perhaps Sarah might have backed off from introducing departures in the first settling attempt and instead have encouraged the parents to do what they usually do, using this to understand what matters to them. In contrast with entry into a shared space of reasons, as described by Rai $(2014,2016)$, these parents were not sufficiently aware of Sarah's reasons for proposing points of departure. Prior studies show how in these services, a new approach is often rehearsed first, making professional reasoning available in a situation where this can be questioned and clarified (Hopwood \& Clerke, 2016). This is more difficult during a 'live' settling period. Despite Sarah explaining as she went along, the parents were distracted by Rachel's crying and wakefulness. Equally, the short prelude before the attempt to settle meant that Sarah did not have sufficient understanding of the parents' reasons for settling Rachel in particular ways.

Some of the parents' earlier comments suggest they were ready to challenge their compliant stance; however, this turned out to be a miscue. Arguably Sarah was eager to make the most of the opportunities to support the parents in new practices. What might have appeared as sufficient 
understanding of what matters to the parents ("We are suckers! We concede too much.") did not represent differences and dependences that had consequence (Carlile, 2004). The analysis thus indicates that the risks associated with professional attempts to challenge clients when the illusion of common knowledge is present, and the means to test its robustness require a deviation from institutionally established practices. Stepping back from deliberation and departure, and 'just' watching parents in a settling sequence would constitute precisely such a deviation in all the settings studied.

Sophie's work with Masha is strikingly different: Sophie works at eliciting what matters to Masha and aligning her own motives with Masha's. This requires significant effort as Masha's concern to lose weight and her instinct to cocoon her child are in tension with Sophie's concerns about both the parent's and child's wellbeing. Despite these differences, Sophie's responses and prompts establish forms of common knowledge that become resources for the adults to work together on in a number of more specific problems. This is represented, with reference to common knowledge and associated concepts, in Figure 2.

Figure 2 Collaboration resourced by multiple forms of common knowledge (CK)

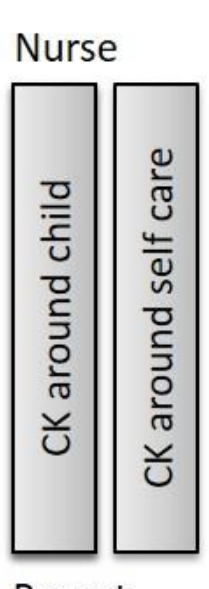

Parent

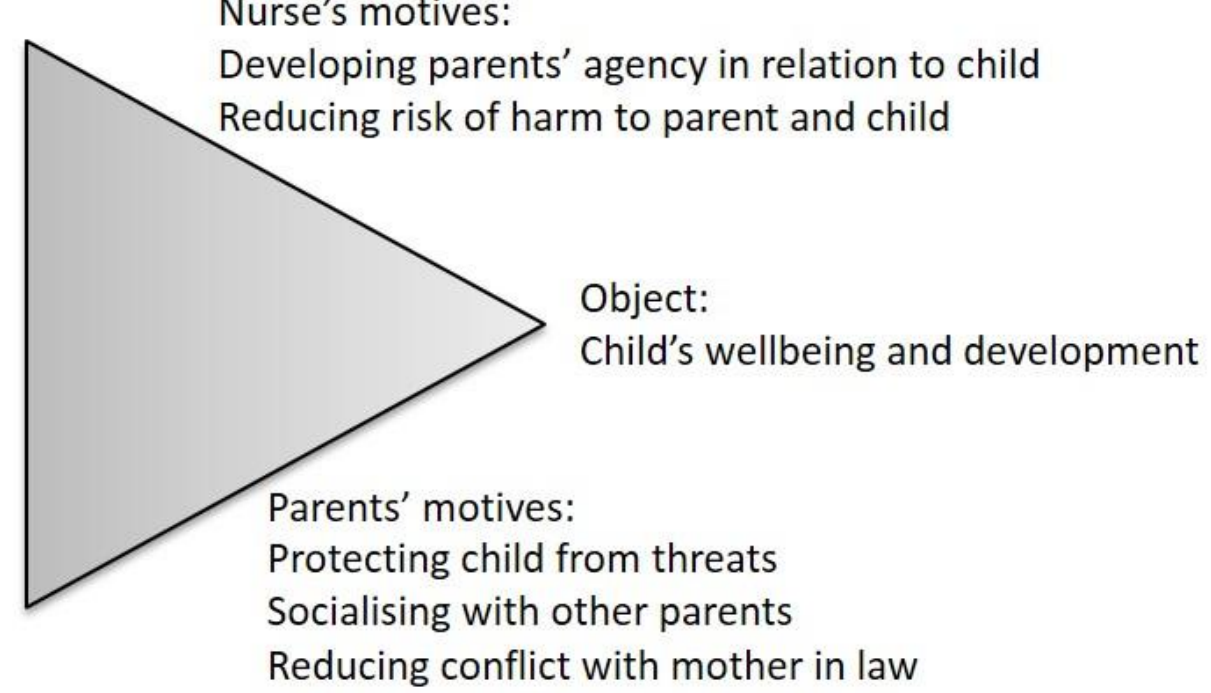

Not all of 'what matters' to Masha is taken up by Sophie, who repeatedly turns the interaction away from the mother-in-law and towards issues where she can build the mother's agency in relation to the child and her self-care. Masha's frequent deixis of intra-familial conflict is not significantly delineated or brought to deliberation. But Sophie does define and deliberate many other issues. Based on prior visits, Sophie is aware of how important it is to Masha that threats to Morgan's 
health are avoided. She presents an aligned and empathetic stance when she delineates what Masha nominates for discussion. She normalises Morgan's not pooing for two days, and places Morgan in a 'normal' category of babies who are playful at an early age and connects this with Masha's maternal agency ("That's a wonderful gift you're giving him").

Sophie frequently asks Masha for more information in a way that elucidates the mother's reasoning. Thus she takes issues that Masha nominates, legitimises them, and directs their delineation towards fuller understanding from the mother's perspective. This reveals how particular instances connect with Masha's deeper motives, and makes explicit Masha's own forms of insight and agency as a parent.

Sophie also infuses delineation and deliberation with comments that make her professional reasoning explicit. Often this directly challenges Masha's views, as when she explains why some extra weight might be important. Sophie's challenge draws on and contributes to common knowledge: framing weight gain as something that is good for Morgan and aligned with what matters to Masha. Sophie's focus on building Masha's agency in her relationship with Morgan is ever present. Often, the route to Sophie's reasoning follows a path from descriptions or insights that Masha provides, as when the boy's increasing weight is used to suggest the need to use the pram as a way for Masha to care for herself physically and to enable social contact. When safety concerns are at issue, Sophie is more assertive and directive. She takes control of the interaction by repeatedly coming back to further delineate the issue of the balcony, and presenting clear instructions as to what to do in future. Even so, she finds a way to solicit and reveal Masha's own agency in this regard, asking "What can you do?"

This confirms the importance of common knowledge and being able to make visible differences that are now jointly recognised to be of relevance and consequence to what matters to both parties. What is remarkable about Sophie's work with Masha is not the absence of difference, but the way in which difference plays out between them. Acceptable points of departure are reached through careful work that elicits differences and frames them in terms of what matters.

In Sarah's work with the Kelly family, topics were relatively stable and linear in sequence. However, the absence of common knowledge in the settling work means that it did not progress, but kept looping back to further deliberation as the parents resisted points of departure. In Sophie's work with Masha, the structure was much messier, with both the parent and professional looping 
back to topics discussed previously. However, the joint work did progress through delineation towards deliberation, departure and signs of development. Furthermore, there were instances where departures led to further deliberations which then enabled new departures, so the recursive process has an expansive, resourcing effect.

\section{Conclusion}

This paper adds to a nascent body of work that builds fresh understandings of professional-client collaboration in terms of common knowledge. It highlights the crucial role of clients' and professionals' motives. While existing partnership models do not dismiss questions of motive, there is a risk that they are treated unproblematically, assuming it is sufficient to have professionals who seek positive outcomes for families, and who can support parents acting towards their goals. Equally, while frameworks such as FPM explicitly point to the need to work with difference, it is not always clear how differences are to be dealt with.

Middleton's (2010) D-analysis affords a granular inspection of interactions. The D-approach to participants' concerns is consistent with Edwards's (2016) attention to what matters. The high resolution of the D-analysis helps to link the sequences and consequences of communicative action with broader questions of how professionals and clients accomplish collaboration, capturing the strategies used by professionals to elicit clients' concerns and make their agency explicit.

The D-analysis contributes to understandings of common knowledge by revealing how it unfolds recursively, looping back to topics that have been previously stated and discussed. This can function productively, as progress towards departure in one aspect can resource definition and deliberation in another. This non-linearity also connects with particular qualities of professionalclient relationships. Rapid movement between substantive foci can reflect the professional's willingness to follow the clients' concerns, even when this creates a chaotic structure and makes the work particularly demanding. It can also reflect the professional's efforts to reclaim or redirect communicative action towards their priorities. This shows that professional-client collaboration is a complex, emergent phenomenon located in practices and specific settings, rather than something that can be reduced to a procedural prescription.

This D-analysis specifically elucidates struggles to build common knowledge in families with young children, highlighting why such work is complex and demanding for professionals (and 
indeed, clients). The present analysis shows how specific and potentially precarious the conditions for progressing from deliberation to departure (and hopefully, development) are. Common knowledge shores up this crucial shift when used as a resource where clients can accept challenges introduced by professionals because they recognise them as aligned with their concerns. This paper thus reveals the skilful nature of work done to build common knowledge, and its importance in processes through which professionals help clients step towards gaining control over their child's trajectory and developing the capacity to use resources that support them and the child.

Bovaird et al. (2016) note the capacity of policy to 'nudge' towards greater participation in collective co-production. Our findings suggest the need to balance this with efforts that looks inwards, at the way professional-client interactions unfold. This recasts active user involvement beyond existing typologies (Voorberg et al., 2014). The client's contribution may be conceptualised as that of a co-collaborator through joint communicative work and reciprocal learning. But as we have seen, the client role can also become one of contestation, resistance and struggle. The Danalysis points to the significance of communicative effort on the part of both client and professional: nominating issues that are important, taking them up, elaborating, defining, debating, moving together towards new insights that form the basis of departure. Thus, the paper highlights just how demanding co-production can be, for both parties, and offers a distinctive and sensitive set of conceptual tools for elucidating how participants communicatively negotiate the interaction.

\section{Acknowledgements}

This research was funded by the Australian Research Council (Project No. DE150100365). The authors wish to thank staff and clients at Karitane, Tresillian and Northern Sydney Local Health District for their generous participation. The study was approved by South Western Sydney Local Health District Research and Ethics Office (HREC/15/LPOOL/77) and by the University of Technology Sydney HREC (2015000284).

\section{Endnotes}

${ }^{1}$ Engeström (2008) describes co-configuration as a historically new form of practice. This is related to ideas of co-production, but is tied conceptually to system-level analysis associated with CulturalHistorical Activity Theory, and so does not fall within the scope of the present analysis.

${ }^{2}$ Goals may also be distinguished theoretically within a cultural-historical framework. While (collective) activity is directed towards an object, individual action is directed towards a goal 
(Leont'ev, 1978).

\section{References}

Baggens, C. A. L. (2004). The institution enters the family home: Home visits in Sweden to new parents by the child health care nurse. Journal of Community Health Nursing, 21(1), 15-27. doi:10.1207/s15327655jchn2101_2

Bovaird, T., Stoker, G., Jones, T., Loeffler, E., \& Pinilla Roncancio, M. (2016). Activating collective co-production of public services: Influencing citizens to participate in complex governance mechanisms in the UK. International Review of Administrative SCiences, 62(1), 47-68. doi: 10.1177/0020852314566009

Bovaird, T., Van Ryzin, G. G., Loeffler, E., \& Parrado, S. (2015). Activating citizens to participate in collective co-production of public services. Journal of Social Policy, 44(1), 1-23. doi:10.1017/S0047279414000567

Bradwell, P., \& Marr, S. (2008). Making the most of collaboration: an international survey of public service co-design. London: Demos / Price Waterhouse Coopers.

Carlile, P. R. (2004). Transferring, translating and transforming: An integrative framework for managing knowledge across boundaries. Organization Science, 15(5), 555-568.

Casimiro, L. M., Hall, P., Kuziemsky, C., O'Connor, M., \& Varpio, L. (2015). Enhancing patientengaged teamwork in healthcare: An observational case study. Journal of Interprofessional Care, 29(1), 55-61. doi:10.3109/13561820.2014.940038

Davis, H., \& Fallowfield, L. (1991). Counselling and communication in health care. London: Wiley.

Davis, H., \& Meltzer, L. (2007). Working with parents in partnership. London: Department for Education and Skills. http://dera.ioe.ac.uk/15598/1/working_with_parents_in_partnership.pdf/ Accessed 03.11.16.

Day, C., Ellis, M., \& Harris, L. (2015). Family Partnership Model: Reflective practice handbook (2nd ed.). London: Centre for Parent and Child Support, South London and Maudsley NHS Foundation Trust.

Day, C., \& Harris, L. (2013). The Family Partnership Model: Evidence-based effective partnerships. Journal of Health Visiting, 1(1), 54-59. doi:10.12968/johv.2013.1.154

Derry, J. (2008). Abstract rationality in education: From Vygotsky to Brandom. Studies in Philosophy and Education, 27, 49-62. doi:10.1007/s11217-007-9047-1

Edwards, A. (2005). Relational agency: Learning to be a resourceful practitioner. International Journal of Educational Research, 43(3), 168-182. doi:10.1016/j.ijer.2006.06.010 
Edwards, A. (2007). Working collaboratively to build resilience: A CHAT approach. Social Policy \& Society, 6(2), 255-264. doi:10.1017/S1474746406003514

Edwards, A. (2009). Relational agency in collaborations for the well- being of children and young people. Journal of Children's Services, 4(1), 33-43. doi:10.1108/17466660200900004

Edwards, A. (2010). Being an expert practitioner: The relational turn in expertise. Dordrecht: Springer.

Edwards, A. (2011). Building common knowledge at the boundaries between professional practices: Relational agency and relational expertise in systems of distributed expertise. International Journal of Educational Research, 50(1), 33-39. doi:10.1016/j.ijer.2011.04.007

Edwards, A. (2012). The role of common knowledge in achieving collaboration across practices. Learning, Culture and Social Interaction, 1, 22-32. doi:10.1016/j.1csi.2012.03.003

Edwards, A. (2016). Revealing relational work. In A. Edwards (Ed.), Working relationally in and across practices: Cultural-historical approaches to collaboration (pp. 1-21). Cambridge: Cambridge University Press.

Elkan, R., Blair, M., \& Robinson, J. J. A. (2000). Evidence-based practice and health visiting: The need for theoretical underpinnings for evaluation. Journal of Advanced Nursing, 31(6), 1316-1323. doi:10.1046/j.1365-2648.2000.01423.x

Engeström, Y. (2008). From teams to knots: Activity-theoretical studies of collaboration and learning at work. Cambridge: Cambridge University Press.

Ewert, B., \& Evers, A. (2012). Co-production: Contested meanings and challengers for user organisations. In V. Pestoff, T. Brandsen, \& B. Vershuere (Eds.), New public governance, the third sector and co-production (pp. 61-78). Abingdon: Routledge.

Feeley, N., \& Gottlieb, L. N. (2000). Nursing approaches for working with family strengths and resources. Journal of Family Nursing, 6(1), 9-24. doi:10.1177/107484070000600102

Fowler, C., Dunston, R., Lee, A., Rossiter, C., \& McKenzie, J. (2012). Reciprocal learning in partnership practice: An exploratory study of a home visiting program for mothers with depression. Studies in Continuing Education, 34(2), 99-112. doi:10.1080/0158037X.2011.611800

Fowler, C., \& Lee, A. (2007). Knowing how to know: Questioning 'knowledge transfer' as a model for knowing and learning in health. Studies in Continuing Education, 29(2), 181-193. doi:10.1080/01580370701403399

Fowler, C., Lee, A., Dunston, R., Chiarella, M., \& Rossiter, C. (2012). Co-producing parenting practice: Learning how to do child and family health nursing differently. Australian 
Journal of Child and Family Health Nursing, 9(1), 7-11.

Fowler, C., Rossiter, C., Bigsby, M., Hopwood, N., Lee, A., \& Dunston, R. (2012). Working in partnership with parents: The experience and challenge of practice innovation in child and family health nursing. Journal of Clinical Nursing, 21(21-22), 3306-3314. doi:10.1111/j.1365-2702.2012.04270.x

France, A., \& Utting, D. (2005). The paradigm of 'risk- and protection-focused prevention' and its impact on services for children and families. Children and Society, 19(2), 77-90. doi:10.1002/CHI.870

Gannon, L., \& Lawson, N. (2008). Co-production: The modernisation of public services by staff and users. London: Compass.

Hall, C., Slembrouck, S., Haigh, E., \& Lee, A. (2010). The management of professional roles during boundary work in child welfare. International Journal of Social Welfare, 19(3), 348-357. doi:10.1111/j.1468-2397.2010.00725.x

Harris, L., Wood, L., \& Day, C. (2014). An ethnographic study into the Family Partnership Model: Implementation and sustainability. London: Centre for Parent and Child Support/South London and Maudsley NHS Foundation Trust.

Heritage, J., \& Sefi, S. (1992). Dilemmas of advice: Aspects of the delivery and reception of advice in interaction between health visitors and first-time mothers. In P. Drew \& J. Heritage (Eds.), Talk at work: Interaction in institutional settings (pp. 359-417). Cambridge: Cambridge University Press.

Hook, M. L. (2006). Partnering with patients - a concept ready for action. Journal of Advanced Nursing, 56(2), 133-143. doi:10.1111/j.1365-2648.2006.03993.x

Hopwood, N. (2014). Four essential dimensions of workplace learning. Journal of Workplace Learning, 26(6/7), 349-363. doi:10.1108/JWL-09-2013-0069

Hopwood, N. (2015). Understanding partnership practice in primary health as pedagogic work: What can Vygotsky's theory of learning offer? Australian Journal of Primary Health, 21(1), 9-13. doi:10.1071/PY12141

Hopwood, N. (2016a). Expertise, learning, and agency in partnership practices in services for families with young children. In A. Edwards (Ed.), Working relationally in and across practices: Cultural-historical approaches to collaboration (pp. 25-42). Cambridge: Cambridge University Press.

Hopwood, N. (2016b). Professional practice and learning: Times, spaces, bodies, things. Dordrecht: Springer.

Hopwood, N., \& Clerke, T. (2016). Professional pedagogies of parenting that build resilience 
through partnership with families at risk: A cultural-historical approach. Pedagogy, Culture \& Society, 24(4), 599-615. doi:10.1080/14681366.2016.1197299

Hopwood, N., Day, C., \& Edwards, A. (2016). Partnership practice as collaborative knowledge work: Overcoming common dilemmas through an augmented view of professional expertise. Journal of Children's Services, 11(2), 111-123. doi:10.1108/JCS-08-2015-0027

Hopwood, N., Fowler, C., Lee, A., Rossiter, C., \& Bigsby, M. (2013). Understanding partnership practice in child and family nursing through the concept of practice architectures. Nursing Inquiry, 20(3), 199-210. doi:10.1111/nin.12019

Leont'ev, A. N. (1978). The problem of activity in psychology. Activity, consciousness and personality. Upper Saddle River, NJ: Prentice Hall.

Middleton, D. (2010). Identifying learning in interprofessional discourse: The development of an analytic protocol. In H. Daniels, A. Edwards, Y. Engeström, T. Gallagher, \& S. Ludvigsen (Eds.), Activity theory in practice: Promoting learning across boundaries and agencies (pp. 90-104). London: Routledge.

Needham, C., \& Carr, S. (2009). Co-production: An emerging evidence base for adult social care transformation, Research Briefing 31. London: Social Care Institute for Excellence.

NSW Health. (2010a). Families NSW Supporting Families Early package: SAFE START strategic policy. Sydney: NSW Department of Health. http://www0.health.nsw.gov.au/policies/pd/2010/pdf/PD2010_016.pdf/ Accessed 03.11.16.

NSW Health. (2010b). Maternal \& child health primary health care policy. Sydney: NSW Ministry of Health. http://www0.health.nsw.gov.au/policies/pd/2010/pdf/PD2010_017.pdf/ Accessed 03.11.16.

NSW Health. (2011). Child and family health nursing: professional practice framework 2011-2016. Sydney: NSW Department of Health. http://www.health.nsw.gov.au/nursing/projects/Publications/child-and-family-healthpractice-framework.pdf/ Accessed 03.11.16.

Nuttall, J. (2013). Inter-professional work with young children in hospital: The role of 'relational agency'. Early Years: An International Research Journal, 33(4), 413-425. doi:10.1080/09575146.2013.830283

Ostrom, V., \& Ostrom, E. (1977). Public goods and public choices. In E. Savas (Ed.), Alternatives for delivering public services: Toward improved performance (pp. 7-49). Boulder, CO: Westview Press.

Parrado, S., Van Ryzin, G. G., Bovaird, T., \& Löffler, E. (2013). Correlates of co-production: Evidence from a five-nation survey of citizens. International Public Management Journal, 
16(1), 85-112. doi:10.1080/10967494.2013.796260

Rai, P. (2014). Building common knowledge: A cultural-historical analysis of pedagogical practices in a rural primary school in Rajasthan. (DPhil thesis), University of Oxford.

Rai, P. (2016). Building and using common knowledge for building school-community links. In A.

Edwards (Ed.), Working relationally in and across practices: Cultural-historical approaches to collaboration. Cambridge: Cambridge University Press.

Ryan, B. (2012). Co-production: Option or obligation? Australian Journal of Public Administration, 71(3), 314-324. doi:10.1111/j.1467-8500.2012.00780.x

Stuart, K. (2014). Collaborative agency to support integrated care for children, young people and families: An action research study. International Journal of Integrated Care, 14(Apr-May), $1-13$.

Voorberg, W. H., Bekkers, V. J. J. M., \& Tummers, L. G. (2014). A systematic review of cocreation and co-production: Embarking on the social innovation journey. Public Management Review, 17(9), 1333-1357. doi:10.1080/14719037.2014.930505

Vygotsky, L. S. (1960/1997). The history of the development of higher mental functions, Chapter 2: Research method. In R. Rieber \& J. Wollock (Eds.), The collected works of L. S. Vygotsky, Vol. 4: The history of the development of higher mental functions (pp. 27-63). London: Plenum Press.

Wright, L. M., \& Leahey, M. (2009). Nurses and families: A guide to family assessment and intervention (5th ed.). Philadelphia: F. A. Davis. 